\title{
Lynx1 Prevents Long-Term Potentiation Blockade and Reduction of Neuromodulator Expression Caused by $\mathrm{A} \beta_{1-42}$ and JNK Activation
}

\author{
M. L. Bychkov ${ }^{1,2}$, N. A. Vasilyeva1, M. A. Shulepko' ${ }^{1,2}$, P. M. Balaban ${ }^{3}$, M. P. Kirpichnikov ${ }^{1,2}$, \\ E. N. Lyukmanova $a^{1,2^{*}}$ \\ 'Lomonosov Moscow State University, Leninskie Gori 1, Moscow, 119234, Russia \\ 2Shemyakin-Ovchinnikov Institute of Bioorganic Chemistry, Russian Academy of Sciences, Miklucho- \\ Maklaya Str., 16/10, Moscow, 117997, Russia \\ ${ }^{3}$ Institute of Higher Nervous Activity and Neurophysiology, Russian Academy of Sciences, Butlerova \\ Str., 5A, Moscow, 117485, Russia \\ *E-mail: ekaterina-lyukmanova@yandex.ru. \\ Received March 18, 2018; in final form June 27, 2018 \\ Copyright $\odot 2018$ Park-media, Ltd. This is an open access article distributed under the Creative Commons Attribution License, which permits \\ unrestricted use, distribution, and reproduction in any medium, provided the original work is properly cited.
}

\begin{abstract}
Nicotinic acetylcholine receptors (nAChRs) are ligand-gated ion channels. Many neurodegenerative diseases are accompanied by cognitive impairment associated with the dysfunction of $n A C h R s$. The human membrane-tethered prototoxin Lynx1 modulates $\mathrm{AChR}$ function in the brain areas responsible for learning and memory. In this study, we have demonstrated for the first time that the $\beta$-amyloid peptide $A \beta_{1-42}$ decreases Lyn $x 1$ mRNA expression in rat primary cortical neurons, and that this decrease is associated with the activation of c-Jun $\mathbf{N}$-terminal kinase (JNK). In addition, we have demonstrated that the Lyn 1 expression decrease, as well as the blockade of the long-term potentiation underlying learning and memory, caused by $A \beta_{1-42}$, may be prevented by incubation with a water-soluble Lynx1 analogue. Our findings suggest that the water-soluble Lynx1 analogue may be a promising agent for the improvement of cognitive deficits in neurodegenerative diseases. KEYWORDS nicotinic acetylcholine receptor, cognitive impairment, Alzheimer disease, $\beta$-amyloid peptide, Ly6/uPAR.

ABBREVIATIONS ACSF - artificial cerebrospinal fluid, AD - Alzheimer disease, HFS - high-frequency stimulation, LTP - long-term potentiation, fEPSPs - field excitatory postsynaptic potentials, $A \beta$ - $\beta$-amyloid peptide, nAChR - nicotinic acetylcholine receptor, siRNA - small interfering RNA, ws-Lynx1 - water-soluble Lynx1.
\end{abstract}

\section{INTRODUCTION}

Many neurodegenerative diseases, such as Alzheimer's disease $(\mathrm{AD})$, are characterized by impaired cognitive processes associated with the dysfunction of nicotinic acetylcholine receptors ( $\mathrm{nAChRs)}$ [1]. In $\mathrm{AD}$, oligomers of the $\beta$-amyloid peptide $(A \beta)$ form plaques and the most toxic $A \beta$ is $A \beta_{1-42}$ [1]. $A \beta_{1-42}$ in a $200 \mathrm{nM}$ concentration inhibits $\alpha 7-\mathrm{nAChR}$, the most common nicotinic cholinergic receptor in the brain; and the interaction between $A \beta$ and the receptor leads to internalization of the latter in $\mathrm{AD}[1]$. In addition, $\mathrm{A} \beta$ inhibits the longterm potentiation (LTP) [2] that is a generally established model for the plasticity processes underlying memory and learning [3].

Previously, we demonstrated that a water-soluble variant of the human protein Lynx1 (ws-Lynx1) [4], which modulates the $\alpha 7-\mathrm{nAChR}$ function in the brain [5], competes with $A \beta_{1-42}$ for binding to $\alpha 7-\mathrm{nAChR}$ [6]. Pre-incubation of mouse cortical neurons with wsLynx1 was shown to reduce the cytotoxic effect of $\mathrm{A} \beta_{1-42}$ [6]. In addition, Western blot analysis revealed a reduced Lynx1 expression in the cortex of AD modeling transgenic mice $(3 \times \mathrm{Tg}-\mathrm{AD})$ compared to wild-type mice [6]. Based on these facts, we argue that Lynx1 plays an important role in $\mathrm{AD}$, and that the accumulation of $\mathrm{A} \beta_{1-42}$ down-regulates the expression of this neuromodulator in the brain and disturbs the $A \beta_{1-42} /$ Lynx1 balance, causing $\alpha 7-n A C h R$ dysfunction. We studied the effect of $A \beta_{1-42}$ on Lynx 1 gene expression in rat primary cortical and hippocampal neurons and evaluated the effect of ws-Lynx1 and A $\beta_{1-42}$ on LTP in mouse hippocampal slices. 


\section{EXPERIMENTAL}

A primary neuron culture was prepared from the cortex and hippocampus of newborn Wistar rats according to the previously described procedure [7]. On the $14^{\text {th }}$ day, the neuron culture was supplemented with either $\mathrm{A} \beta_{1-42}$ (1 or $5 \mu \mathrm{M}$, Biopeptide Co) oligomerized according to the previously described protocol [8], or $5 \mu \mathrm{M}$ $\mathrm{A} \beta_{42-1}$ (reverse peptide used as a negative control; $\mathrm{Bi}-$ opeptide Co), or $10 \mu \mathrm{M}$ ws-Lynx1 (prepared according to [4]), or a mixture (5 $\mu \mathrm{M} A \beta_{1-42}+10 \mu \mathrm{M}$ ws-Lynx1), or $2.5 \mu \mathrm{M}$ SP600125 (Tocris), or a mixture (5 $\mu \mathrm{M} \mathrm{A} \beta_{1-42}+$ $2.5 \mu \mathrm{M}$ SP600125) and incubated for an additional $24 \mathrm{~h}$. For JNK knockdown, on the $10^{\text {th }}$ day cortical neurons were transfected with JNK1 and JNK2 small interfering RNAs (siRNAs) or with the control siRNA (Table 1). After that, the neurons were incubated for $72 \mathrm{~h}$, then they were supplemented with $5 \mu \mathrm{M} A \beta_{1-42}$ and incubated for another $24 \mathrm{~h}$.

Then, the total mRNA was isolated using an ExtractRNA reagent (Evrogen). The mRNA was treated with DNase I (Thermo Fisher Scientific, USA), and cDNA was then synthesized using a MMLV RT kit (Evrogen). Real-time PCR was carried out using a 5x mixture of qPCRmix-HS SYBR + HighROX (Evrogen); the list of primers is given in Table 2 . The data were analyzed using the LinReg 2017.0 software. The mRNA level was normalized to the $\beta$-actin values.

Transversal hippocampal slices from eight-monthold C57BL/ 6 mice were perfused with an artificial cerebrospinal fluid (ACSF) (124 $\mathrm{mM} \mathrm{NaCl}, 3 \mathrm{mM} \mathrm{KCl}$, $2.5 \mathrm{mM} \mathrm{CaCl}_{2}, 1.3 \mathrm{mM} \mathrm{MgCl}_{2}, 26 \mathrm{mM} \mathrm{NaHCO}_{3}, 1.27 \mathrm{mM}$ $\mathrm{NaH}_{2} \mathrm{PO}_{4}$, and $10 \mathrm{mM} D$-glucose, pH 7.4), continuously saturated with carbogen $\left(95 \% \mathrm{O}_{2}+5 \% \mathrm{CO}_{2}\right)$ at $34{ }^{\circ} \mathrm{C}$ for $1 \mathrm{~h}$. Then, a portion of the slices was perfused with ACSF containing $200 \mathrm{nM} \mathrm{A} \beta_{1-42}$ and the other was perfused with ACSF containing $200 \mathrm{nM} A \beta_{1-42}+2 \mu \mathrm{M}$ wsLynx1 for $1 \mathrm{~h}$. Control slices were perfused with ACSF without $A \beta_{1-42}$ and ws-Lynx1. Field excitatory postsynaptic potentials (fEPSPs) were recorded using a SliceMaster system (Scientifica, UK) at $32^{\circ} \mathrm{C}$. A recording electrode (1-3 M $\Omega$ ) filled with $\mathrm{ACSF}$ was positioned within hippocampal CA1 stratum radiatum. Synaptic responses were evoked by paired-pulse stimulation of Schaffer collaterals in the CA3 stratum radiatum area by using a bipolar electrode. A 50-ms interpulse interval was used, unless stated otherwise. The simulations
Table 1. The small interfering RNAs used in the study

\begin{tabular}{|c|c|}
\hline \multirow{2}{*}{ Gene } & Interfering RNA sequence \\
\hline \multirow{2}{*}{ Control } & UUCUCCGAACGUGUCACGUTT \\
\cline { 2 - 2 } & ACGUGACACGUUCGGAGAATT \\
\hline \multirow{2}{*}{ JNK1 } & GGCAUGGGCUAUAAAGAAATT \\
\cline { 2 - 2 } & UUUCUUUGUAGCCCAUGCCTT \\
\hline \multirow{2}{*}{ JNK2 } & GCCAGAGACUUAUUAUCAATT \\
\cline { 2 - 2 } & UUGAUAAUAAGUCUCUGGCTT \\
\hline
\end{tabular}

were repeated at $0.033 \mathrm{~Hz}$. Stimulus intensity was adjusted to elicit $40 \%$ of maximal fEPSP amplitude.

After 20 minutes of recording test responses, a highfrequency stimulation (HFS) protocol was used to induce LTP: 10 trains with a frequency of $100 \mathrm{~Hz}$ (five stimuli per train) with an intertrain interval of $200 \mathrm{~ms}$, four sessions with an interval of $30 \mathrm{~s}$. After LTP induction, fEPSPs were recorded for $1.5 \mathrm{~h}$. The obtained data were recorded, filtered, and analyzed using the Spike2 software (Cambridge Electronic Design Limited, UK) and SigmaPlot 11.0 (Systat Software Inc., USA). The post-tetanic tangent of the fEPSP slope was normalized to the mean slope of all fEPSPs recorded 20 min before LTP induction.

The statistical analysis of the LTP data and the data on the effect of $\mathrm{A} \beta_{1-42}$, ws-Lynx1, SP600125, and siRNA on gene expression in primary neurons was performed using the GraphPad Prism 6.0 (GraphPad Software Inc.) software. A value of $p<0.05$ was considered statistically significant. All experiments were performed in accordance with the guidelines set forth by the European Communities Council Directive of November 24, 1986 (86/609/EEC) and were approved by the ethical committees of the Shemyakin-Ovchinnikov Institute and Institute of Higher Nervous Activity and Neurophysiology, Russian Academy of Sciences.

\section{RESULTS AND DISCUSSION}

$A \beta_{1-42}$-induced decrease in Lynx 1 expression in neurons is associated with JNK activation

To test the hypothesis of the effect of amyloid peptide on Lynx1 expression, we incubated primary neurons of the rat cortex and hippocampus with $1 \mu \mathrm{M}$ of oli-

Table 2. Primers used in the study

\begin{tabular}{|c|c|c|c|}
\hline Gene & Forward primer & Reverse primer & Length, bp \\
\hline$\beta$-actin & TCATGTTTGAGACCTTCAACAC & GTCTTTGCGGATGTCCACG & 250 \\
\hline Lynx 1 & ACCACTCGAACTTACTTCACC & ATCGTACACGGTCTCAAAGC & 81 \\
\hline$\alpha 7$-nAChR & TGCACGTGTCCCTGCAAGGC & GTACACGGTGAGCGGCTGCG & 112 \\
\hline
\end{tabular}




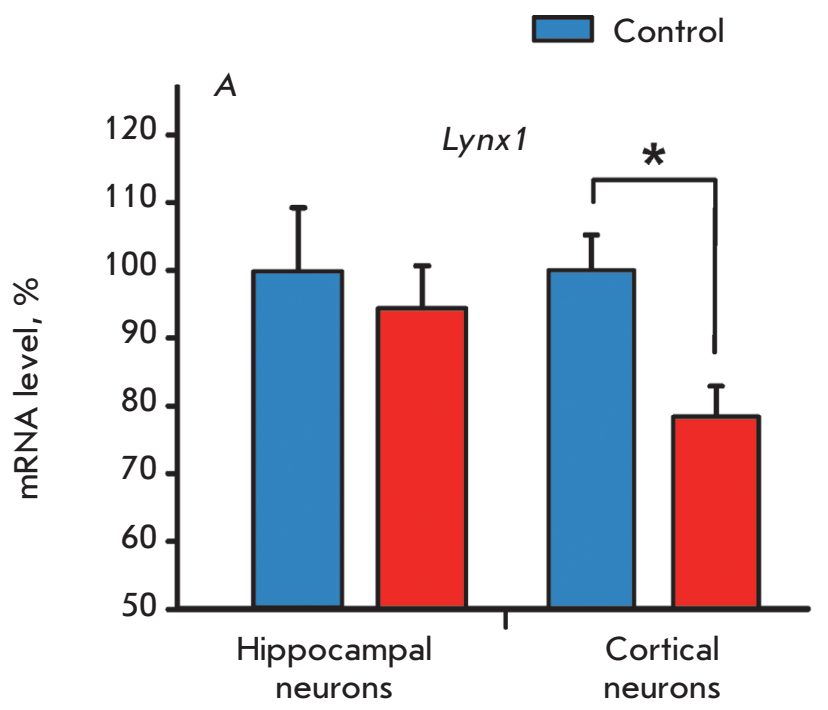

$1 \mu \mathrm{MA} \beta_{1-42}$

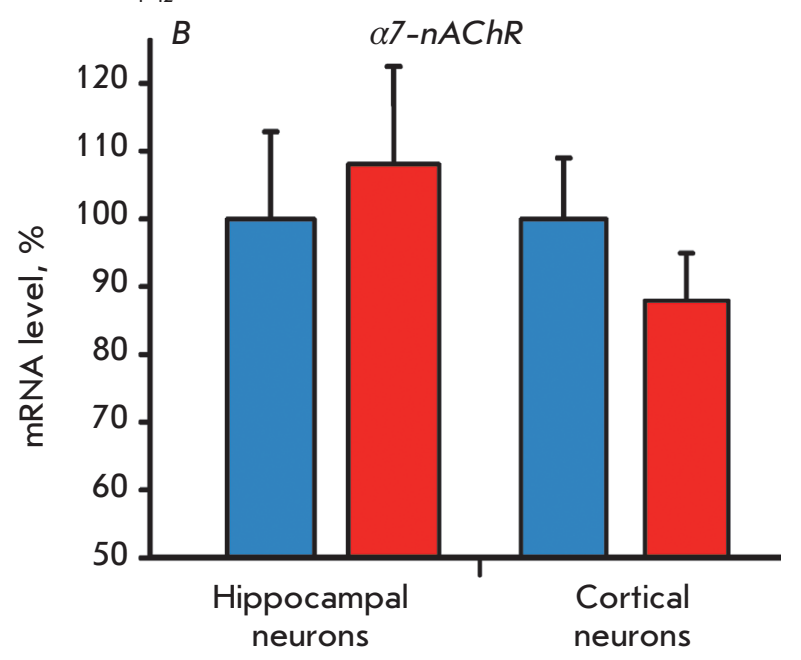

Fig. 1. Effect of $A \beta_{1-42}$ on $\operatorname{Lynx1}(\mathrm{A})$ and $\alpha 7-n A C h R(B)$ gene expression in primary cortical and hippocampal neurons. The data are presented as $\%$ of the control \pm s.e.m. $(n=3)$. Data indicated by ${ }^{*}(p<0.05)$ significantly differ from each other, based on a two-sided t-test

gomeric $\mathrm{A} \beta_{1-42}$ and analyzed the Lynx $1 \mathrm{mRNA}$ level (Fig. 1A). In hippocampal neurons, there was no significant decrease in neuromodulator expression, while a significant reduction in the Lynx 1 mRNA level (up to $78.4 \pm 4.4 \%$ of the control level) was observed in cortical neurons. This is consistent with a previously observed decrease in Lynx1 expression in the cortex of AD modeling mice [6]. In contrast, $A \beta_{1-42}$ did not decrease the $\alpha 7-n A C h R$ mRNA level either in hippocampal or in cortical neurons (Fig. 1B). An increase in the $A \beta_{1-42}$ concentration to $5 \mu \mathrm{M}$ led to a further decrease in Lynx 1 gene expression in cortical neurons (up to $65.8 \pm 4.9 \%$ of the control level, Fig. 2A).

Nicotine-induced activation of $\alpha 7-n A C h R$ can regulate gene transcription through CREB phosphorylation and the activation of MAP/ERK signaling pathways, which is accompanied by an increase in the expression level of the early response c-Fos transcription factor [9]. On the other hand, binding of oligomeric $A \beta_{1-42}$ to $\alpha 7$-nAChR leads to the activation of c-Jun N-terminal kinase (JNK) [10], which plays a key role in the regulation of gene expression and other vital processes, including processing of the $\beta$-amyloid peptide precursor and formation of neurofibrillary tangles in $\mathrm{AD}$ [10]. In turn, JNK activation may lead to the inhibition of CREB transcription factor phosphorylation and, therefore, to a decrease in the expression level of the c-Fos transcription factor [11].

To elucidate whether the decreased Lynx 1 expression level in cortical neurons incubated with oligomeric $\mathrm{A} \beta_{1-42}$ was associated with JNK activation, we incubated cortical neurons with $\mathrm{A} \beta_{1-42}$ and SP600125, a selective inhibitor of JNK1, JNK2, and JNK3 which is considered now as one of the potential drugs for $\mathrm{AD}$ treatment [10]. Indeed, co-incubation of neurons with $\mathrm{A} \beta_{1-42}$ and SP600125 prevented the decrease in Lynx1 expression, indicating a possible association of this decrease with JNK activation (Fig. 2B). To confirm the role of $\mathrm{JNK}$ in the regulation of Lynx 1 transcription, we used knockdown of the JNK1 and JNK2 genes with small interfering RNAs. As expected, incubation of neurons with blocked JNK1 and JNK2 expression in the presence of $A \beta_{1-42}$ led to a recovery of the Lynx 1 mRNA expression level (Fig. 2B). In this case, transfection of the neuronal culture with control siRNA that did not inhibit gene transcription had no effect on the decrease in Lynx $1 \mathrm{mRNA}$ expression caused by $\mathrm{A} \beta_{1-42}$ (data not shown). Knockdown of JNK1 and JNK2 in the absence of $A \beta_{1-42}$ did not cause significant changes in the Lynx 1 expression level (Fig. 2B), which confirms the association of the amyloid peptide, JNK activation, and decreased neuromodulator transcription.

An analysis of the human LYNX1 gene promoter in the human genome browser (chr8: 143841246 chr8: 143879640) and the mouse Lynx1 gene promoter (chr15: 74573409 - chr15: 74603409) revealed two potential binding sites for the AP-1 transcriptional complex formed by the c-Jun and c-Fos transcription factors (Fig. 2C). A $\beta_{1-42}$-induced activation of JNK is simultaneously accompanied by c-Jun activation [10] and c-Fos down-regulation [11]. For that reason, a possible imbalance between c-Jun and c-Fos can cause a disruption in the AP-1 transcriptional complex formation and lead to the decrease in Lynx 1 gene transcription. In accordance with this suggestion, incubation of cortical neurons together with ws-Lynx1 and $A \beta_{1-42}$ was 
A

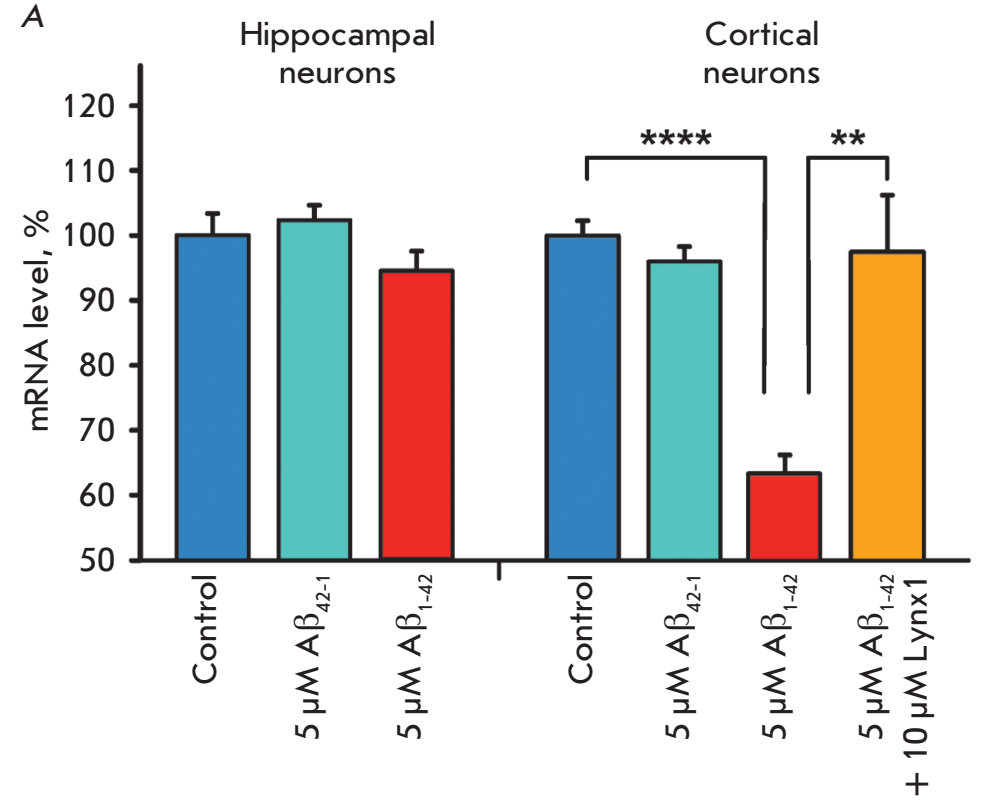

C
Lynx1 promoter

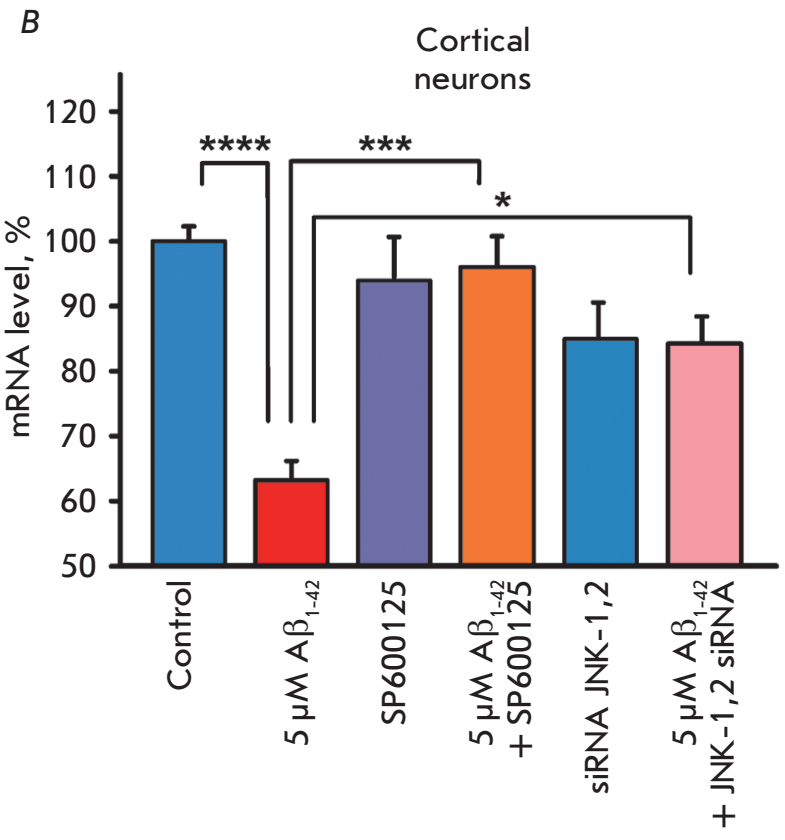

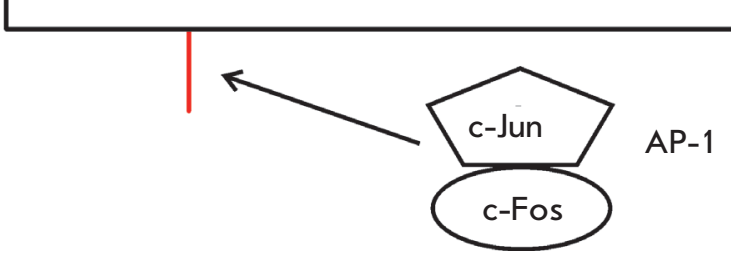

143.879 .640

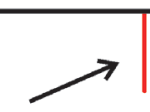

Fig.2. Ws-Lynx 1 and JNK inhibition cancels the decrease in Lynx 1 expression in a primary culture of cortical neurons treated with $A \beta_{1-42}$. (A) Effect of $A \beta_{1-42}, A \beta_{42-1}$, and ws-Lynx 1 on Lynx1 expression. (B) Effect of $A \beta_{1-42}$, JNK inhibition by SP600125, and knockdown of the JNK 1 and JNK2 genes on Lynx 1 expression. The data are presented as \% of the control \pm s.e.m. $(n=4)$. Data indicated by * $(p<0.05),{ }^{* *}(p<0.01)$, and ${ }^{* * * *}(p<0.0001)$ mean a statistically significant difference between groups according to the one-sided ANOVA test, followed by the Tukey's/hoc test. ( $C$ ) Schematic structure of the Lynx1 gene. Red lines denote the c-Jun and c-Fos binding sites.

accompanied by recovery of the Lynx $1 \mathrm{mRNA}$ level (Fig. 2B). Apparently, ws-Lynx1 competes with $\mathrm{A} \beta_{1-42}$ for binding to $\alpha 7-\mathrm{nAChR}$ [6] and activates $\alpha 7-\mathrm{nAChR}$ in a nicotine-like manner, which leads to the c-Fos upregulation [9] and recovery of Lynx 1 transcription.

Ws-Lynx1 prevents $\mathbf{A} \boldsymbol{\beta}_{1-42}$-induced LTP blockade Using SP600125, it was previously demonstrated that the LTP blockade observed during the incubation of hippocampal slices with oligomeric $A \beta_{1-42}$ was associated with JNK activation [12]. To study the effect of Lynx1 on the recovery of the synaptic plasticity impaired by the interaction between oligomeric $A \beta_{1-42}$ and $\alpha 7-n A-$ $\mathrm{ChR}$, as well as JNK activation, we investigated the influence of $200 \mathrm{nM} \mathrm{A} \beta_{1-42}$ on LTP in the surviving mouse's hippocampal slices in the presence and absence of $2 \mu \mathrm{M}$ ws-Lynx1. Pre-perfusion of the slices in a solution containing $A \beta_{1-42}$ for $1 \mathrm{~h}$ led to a significant decrease in the post-tetanic fEPSP, noticeable in the first minutes after LTP induction. In this case, the fEPSP slope averaged over the first 10 minutes of recording decreased almost 1.5-fold compared to the control fEPSP slope (Fig. 3B). A significant decrease in the fEPSP slope caused by $A \beta_{1-42}$ to the baseline fEPSP values was observed during the entire period after LTP induction.

However, incubation of hippocampal slices in a medium containing both $\mathrm{A} \beta_{1-42}$ and ws-Lynx1 restored the LTP level almost to the control values (Fig. 3). The mean fEPSP slope upon simultaneous application of $\mathrm{A} \beta_{1-42}$ and ws-Lynx1 was significantly higher than that of the fEPSP observed during incubation with $A \beta_{1-42}$ alone and was not statistically different from the mean fEPSP slope in the control throughout the recording time after HFS (Fig. 3B). Therefore, ws-Lynx1 prevents the inhibitory effect of $A \beta_{1-42}$ and facilitates the complete recovery of LTP. 
$A$

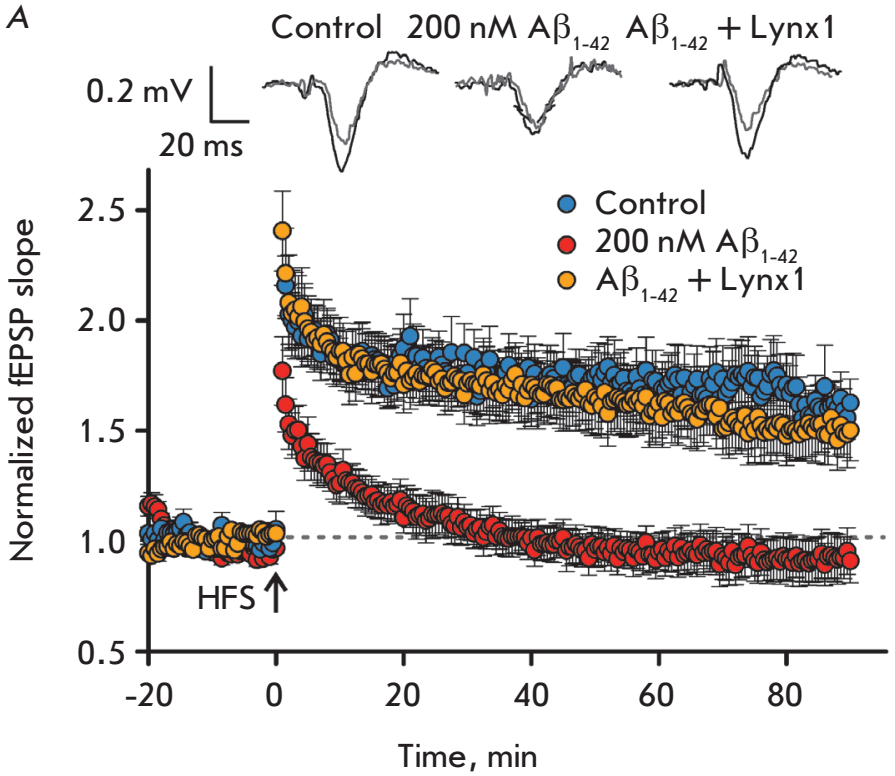

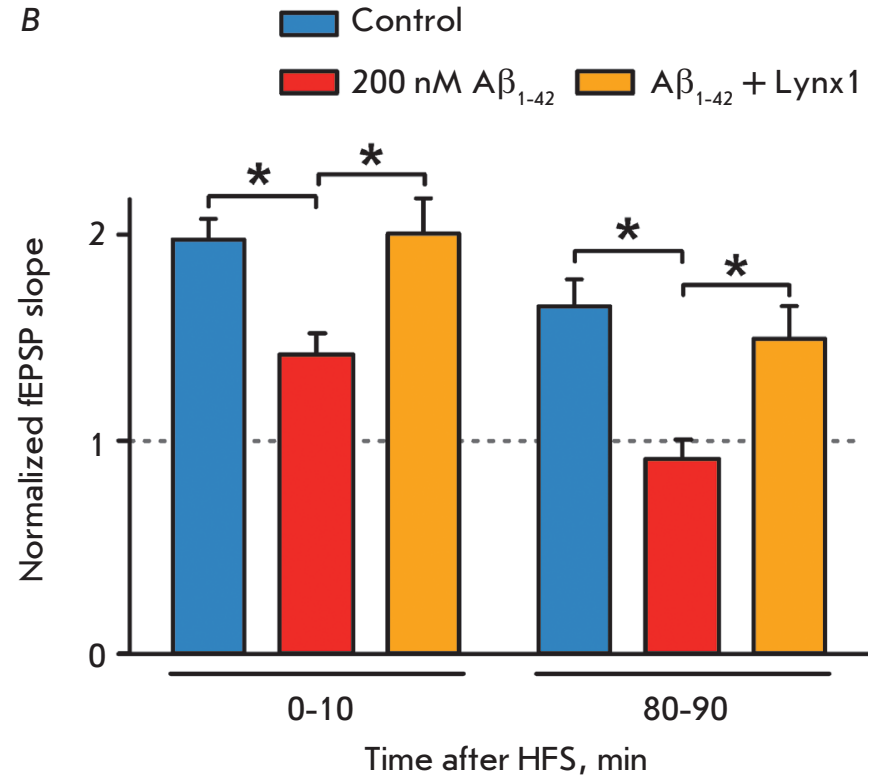

Fig. 3. Ws-Lynx 1 prevents $A \beta_{1-42}$-induced LTP blockade in hippocampal slices. $(A)$ Time course of changes in the fEPSP slope recorded in control hippocampal slices perfused with $A C S F$ without $A \beta_{1-42}(n=8), A C S F$ containing $200 n M A \beta_{1-42}$ $(n=6)$, and ACSF containing $200 \mathrm{nM} \mathrm{A} \beta_{1-42}+2 \mu M$ ws-Lynx1 $(n=5)$. (B) fEPSPs slopes averaged during 0-10 min and 80-90 min after HFS. * $(p<0.05)$ means a statistically significant difference between groups according to the one-way ANOVA test, followed by the Tukey's/hoc test

\section{CONCLUSION}

Hereby, the presence of oligomeric $A \beta_{1-42}$ in the neuronal environment leads to a significant decrease in the expression of the Lynx1 neuromodulator that regulates $\alpha 7-n A C h R$ functioning in the brain. We have demonstrated for the first time that this decrease is associated with JNK activation and can be prevented by incubation with the water-soluble Lynx1 analogue. In addition, ws-Lynx 1 is capable of correcting $A \beta_{1-42}$-induced impairments of hippocampal synaptic plasticity, which underlies memory impairment and other cognitive dysfunctions in AD.

This work was supported by the Russian Foundation for Basic Research (No. 16-34-01302; N.A.V., development of a system for registering currents in brain slices) and Russian Science Foundation (No. 16-14-00102; E.N.L., M.A.Sh., N.A.V., effects of $A \beta_{1-42}, S P 600125$, siRNA, and ws-Lynx 1 on LTP and gene expression).
REFERENCES

1. Buckingham S.D., Jones A.K., Brown L.A., Sattelle D.B. // Pharmacol. Rev. 2009. V. 61. P. 39-61.

2. Walsh D.M., Klyubin I., Fadeeva J.V., Cullen W.K., Anwyl R., Wolfe M.S., Rowan M.J., Selkoe D.J. // Nature. 2002.

V. 416. P. 535-539.

3. Lynch M.A. // Physiol. Rev. 2004. V. 84. P. 87-136.

4. Lyukmanova E.N., Shenkarev Z.O., Shulepko M.A., Mineev K.S., D’Hoedt D., Kasheverov I.E., Filkin S.Y., Krivolapova A.P., Janickova H., Dolezal V., Dolgikh D.A., et al. // J. Biol. Chem. 2011. V. 286. P. 10618-10627.

5. Miwa J.M., Ibanez-Tallon I., Crabtree G.W., Sánchez R., Sali A., Role L.W., Heintz N. // Neuron. 1999. V. 23. P. 105-114.

6. Thomsen M.S., Arvaniti M., Jensen M.M., Shulepko M.A., Dolgikh D.A., Pinborg L.H., Härtig W., Lyukmanova E.N.,
Mikkelsen J.D. // Neurobiol. Aging. 2016. V. 46. P. 13-21.

7. Suntsova M., Gogvadze E.V., Salozhin S., Gaifullin N., Eroshkin F., Dmitriev S.E., Martynova N., Kulikov K., Malakhova G., Tukhbatova G., et al. // Proc. Natl. Acad. Sci. USA. 2013. V. 110. P. 19472-19477.

8. Klein W.L. // Neurochem. Int. 2002. V. 41. P. 345-352.

9. Hu M., Liu Q.S., Chang K.T., Berg D.K. // Mol. Cell. Neurosci. 2002. V. 21. P. $616-625$.

10. Yarza R., Vela S., Solas M., Ramirez M.J. // Front. Pharmacol. 2016. V. 6 doi: 10.3389/fphar.2015.00321.

11. Yenki P., Khodagholi F., Shaerzadeh F. // J. Mol. Neurosci. 2013. V. 49. P. 262-269.

12. Wang Q., Walsh D.M., Rowan M.J., Selkoe D.J., Anwyl R. // J. Neurosci. 2004. V. 24. P. 3370-3378. 